(6)

\section{OPEN ACCESS}

'Section of Gastroenterology and Hepatology, Department of Medicine, Baylor College of Medicine and Michael E. DeBakey Veterans Affairs Medical Center, Houston, Texas, USA

Liver Unit, Hospital Clinic de Barcelona, Universitat de Barcelona, Barcelona, Spain Institut d'Investigacions Biomediques August Pi i Sunyer (IDIBAPS), Barcelona, Spain

${ }^{4}$ Centro d'Investigaciones

Biomedicas en Red, enfermedades Hepaticas y Digestivas (CIBEReHD), Barcelona, Spain

Inserm, U1149, Centre de Recerche sur l'inflammation (CRI), Paris, France

${ }^{6}$ Faculté de Médicine,

Université Paris Diderot, Paris, France

${ }^{7}$ Départment HospitaloUniversitaire (DHU) UNITY, Service d'Hépatologie, Hôpital Beaujon, AP-HP, Clichy, France ${ }^{8}$ Laboratoire d'Excellence (Labex) Inflamex, CUE Sorbonne Paris Cité, Paris, France

${ }^{9}$ European Foundation for the Study of Chronic Liver Failure (EF-CLIF), Barcelona, Spain

\section{Correspondence to} Dr Pere Ginès, Liver Unit, Hospital Clinic of Barcelona, University of Barcelona, Institut d'Investigacions Biomèdiques August Pi I Sunyer (IDIBAPS) Barcelona 08036, Spain PGINES@clinic.cat; pgines@ clinic.ub.es

RM and PG are joint senior authors.

Received 18 July 2016 Revised 10 October 2016 Accepted 13 October 2016 Published Online First 4 January 2017

\title{
Acute-on-chronic liver failure: an update
}

\author{
Ruben Hernaez, ${ }^{1}$ Elsa Solà, ${ }^{2,3,4}$ Richard Moreau, ${ }^{5,6,7,8,9}$ Pere Ginès ${ }^{2,3,4}$
}

\begin{abstract}
Acute-on-chronic liver failure (ACLF) is a syndrome characterised by acute decompensation of chronic liver disease associated with organ failures and high shortterm mortality. Alcohol and chronic viral hepatitis are the most common underlying liver diseases. Up to $40 \%$ $50 \%$ of the cases of ACLF have no identifiable trigger; in the remaining patients, sepsis, active alcoholism and relapse of chronic viral hepatitis are the most common reported precipitating factors. An excessive systemic inflammatory response seems to play a crucial role in the development of ACLF. Using a liver-adapted sequential organ assessment failure score, it is possible to triage and prognosticate the outcome of patients with ACLF. The course of ACLF is dynamic and changes over the course of hospital admission. Most of the patients will have a clear prognosis between day 3 and 7 of hospital admission and clinical decisions such as evaluation for liver transplant or discussion over goals of care could be tailored using clinical scores. Bioartificial liver support systems, granulocyte-colony stimulating factors or stemcell transplant are in the horizon of medical care of this patient population; however, data are too premature to implement them as standard of care.
\end{abstract}

\section{INTRODUCTION}

Cirrhosis is a pathological diagnosis characterised by diffuse fibrosis, severe disruption of the intrahepatic arterial and venous flow, portal hypertension and, ultimately, liver failure. ${ }^{1}$ Traditionally, cirrhosis has been dichotomised in compensated and decompensated, and the transition to decompensated cirrhosis happens when any of the following hallmarks occurs: presence of ascites, variceal haemorrhage and/or hepatic encephalopathy (HE). ${ }^{2}$ Once cirrhosis transitions from the compensated to the decompensated stage, it is associated with short-term survival (3-5 years) and evaluation for liver transplant is recommended in the absence of contraindications. If cirrhosis is mediated by a treatable cause (eg, chronic viral hepatitis, ongoing alcohol consumption, obesity, etc), then patients may have transition from a decompensated to a compensated phase.

The concept of acute-on-chronic liver failure (ACLF) has been widely used in critical care hepatology to study patients who underwent artificial support therapies as a bridge to liver transplantation (LT). ${ }^{3}$ In 2009, the Asian Pacific Association for the Study of the Liver (APASL) provided the first consensus on ACLF, defined as "an acute hepatic insult manifesting as jaundice and coagulopathy, complicated within 4 weeks by ascites and/or encephalopathy". ${ }^{4}$ The 2014 definition was further expanded to include 'high 28-day mortality'. 5 Such initiative led the scientific community to identify new venues of research of a syndrome with extrahepatic organ failure (OF) associated with short-term mortality. The current narrative review will provide insights on the current understanding of ACLF with emphasis on established definitions, epidemiology, pathophysiology and treatment/management options.

\section{Heterogeneity of definitions}

ACLF is a syndrome characterised by acute and severe hepatic abnormalities resulting from different types of insults, in patients with underlying chronic liver disease or cirrhosis but, in contrast to decompensated cirrhosis, has a high short-term mortality, mimicking the prognosis of acute liver failure. Nevertheless, the key terms of the definition 'acute', 'chronic liver' and 'failure' have several variations and, a recent systematic review reported up to 13 definitions of ACLF. $^{6}$ Given this heterogeneity and the importance of identifying patients with ACLF for a more expedited triage and work-up, four major societies/organisations have provided working definitions that, although not consistent, lay the groundwork for future research (table 1) ${ }^{5-9}$ and have been used clinically. ${ }^{1011}$ Overall, the APASL provided the first consensus definition on ACLF in $2009,{ }^{4}$ later updated in 2014. ${ }^{5}$ The main difference with all other definitions is that hepatic insults are only taken in consideration if they lead to liver failure (jaundice and HE).

The North American Consortium for the Study of End-Stage Liver Disease (NACSELD) centred their efforts to understand the factors associated with mortality in hospitalised infected patients with cirrhosis. $^{7}$ Consequently, all other triggers were not considered and the generalisability of their findings to non-infected patients with cirrhosis is unknown. The European Association for the Study of the Liver-chronic liver failure (EASL-CLIF) Consortium and called the EASL-CLIF Acute-on-Chronic Liver Failure in Cirrhosis (CANONIC) study is the most comprehensive registry to understand outcomes on hospitalized patients with cirrhosis. ${ }^{9}$ Similar to NACSELD, the inclusion criteria were patients with cirrhosis, but there were no restrictive inclusion criteria and operational definitions for $O F$ in EASL-CLIF were clearly outlined (table 2).

The CANONIC investigators adapted the Sequential Organ Failure Assessment (SOFA) to their cohort to predict short-term mortality (CLIF-C ACLF, available at http://www.clifresearch. com/ToolsCalculators.aspx)(10). Finally, the World Gastroenterology Organisation (WGO), cognizant of the differences between Western and Eastern definitions, has recently provided some suggestions to improve the operational definition of ACLF and its validity remains to be determined using prospective studies. ${ }^{8}$ 
Table 1 Characteristics of the available definitions for acute-on-chronic liver failure (ACLF)

\begin{tabular}{|c|c|c|c|c|}
\hline & APASL definition $^{45}$ & EASL-CLIF definition $^{9}$ & NACSELD definition ${ }^{7}$ & WGO proposal ${ }^{8}$ \\
\hline $\begin{array}{l}\text { Category of } \\
\text { study that led } \\
\text { to the definition }\end{array}$ & $\begin{array}{l}\text { Report of a consensus involving international experts from } \\
\text { the APASL }\end{array}$ & $\begin{array}{l}\text { Prospective, observational study in } 1343 \text { patients with } \\
\text { cirrhosis admitted to } 29 \text { Liver Units in } 12 \text { European countries } \\
\text { (CANONIC study), in the context of the EASL-CLIF Consortium }\end{array}$ & $\begin{array}{l}\text { Prospective, observational study in } 507 \\
\text { patients with cirrhosis hospitalised in } 18 \\
\text { Liver Units across the USA and Canada, in } \\
\text { the context of the NACSELD Consortium }\end{array}$ & $\begin{array}{l}\text { Report of a consensus involving } \\
\text { international experts from the WGO }\end{array}$ \\
\hline $\begin{array}{l}\text { Population } \\
\text { considered in } \\
\text { the definition }\end{array}$ & $\begin{array}{l}\text { Acute liver deterioration (see below) in patients with } \\
\text { previously diagnosed or undiagnosed chronic liver } \\
\text { disease (including cirrosis) } \\
\text { Both compensated cirrhosis and non-cirrhotic chronic } \\
\text { liver disease (non-alcoholic fatty liver disease, related } \\
\text { chronic hepatic injury or chronic hepatitis with fibrosis, } \\
\text { or fibrosis due to other reasons) qualify as chronic liver } \\
\text { disease }\end{array}$ & $\begin{array}{l}\text { Patients with an acute decompensation of cirrhosis* } \\
\text { - Patients with prior decompensation of cirrhosis are } \\
\text { included }\end{array}$ & $\begin{array}{l}\text { Patients with infection at admission or } \\
\text { during hospital stayt } \\
\text { - Patients with prior decompensation of } \\
\text { cirrhosis are included }\end{array}$ & $\begin{array}{l}\text { Patients with chronic liver } \\
\text { disease with or without } \\
\text { previously diagnosed cirrhosis }\end{array}$ \\
\hline $\begin{array}{l}\text { Population } \\
\text { excluded of the } \\
\text { definition }\end{array}$ & $\begin{array}{l}\text { Patients with bacterial infections } \\
\text { Patients with cirrhosis and known prior } \\
\text { decompensation (jaundice, encephalopathy or ascites) } \\
\text { who develop acute deterioration of their clinical status } \\
\text { that is either related or unrelated to precipitating } \\
\text { events are considered to have acute decompensation } \\
\text { but not ACLF }\end{array}$ & $\begin{array}{l}\text { Admission for scheduled procedure or treatment } \\
\text { Hepatocellular carcinoma outside Milan criteria } \\
\text { Severe chronic extrahepatic diseases } \\
\text { HIV infection; ongoing immunosuppressive treatments }\end{array}$ & $\begin{array}{l}\text { Outpatients with infection } \\
\text { HIV infection } \\
\text { Prior organ transplant } \\
\text { Disseminated malignancies }\end{array}$ & Not stated \\
\hline $\begin{array}{l}\text { A priori criteria } \\
\text { of severity }\end{array}$ & Experts consider the failing liver as the driver of severity & $\begin{array}{l}\text { Pre-specified criteria for organ failure(s) (according to the } \\
\text { CLIF-SOFA scale; see table 2) } \\
\text { - Association of organ failures at enrolment and a } 28 \text {-day } \\
\text { transplant-free mortality of } 15 \% \text { or more }\end{array}$ & $\begin{array}{l}\text { Prespecified criteria for organ failures } \\
\text { (see table 2) }\end{array}$ & $\begin{array}{l}\text { Not developed but stated } \\
\text { CLIF-SOFA 'is an important step } \\
\text { in this direction' }\end{array}$ \\
\hline $\begin{array}{l}\text { Basis of the } \\
\text { definition }\end{array}$ & $\begin{array}{l}\text { Liver failure is defined as jaundice (a serum bilirubin level } \\
\text { of } \geq 5 \mathrm{mg} / \mathrm{dL} \text { ) and coagulopathy (an INR of } \geq 1.5 \text { or } \\
\text { prothrombin activity of }<40 \% \text { ). Liver failure is complicated } \\
\text { within } 4 \text { weeks by clinical ascites and/or encephalopathy } \\
\text { in patients with previously diagnosed or undiagnosed } \\
\text { chronic liver disease (including cirrhosis) }\end{array}$ & $\begin{array}{l}\text { Absence of ACLF because } 28 \text {-day mortality is }<5 \% \text { in } \\
\text { patients with: } \\
\text { - No organ failure } \\
\text { - Single organ failure in patients with a serum creatinine } \\
\text { level of }<1.5 \mathrm{mg} / \mathrm{dL} \text { and no hepatic encephalopathy } \\
\text { - Cerebral failure in patients with a serum creatinine level } \\
\text { of }<1.5 \mathrm{mg} / \mathrm{dL} \\
\text { ACLF grade } 1 \text { because } 28 \text {-day mortality is } 22 \% \text { in patients } \\
\text { with: } \\
\text { - Single kidney failure } \\
\text { - Single liver, coagulation, circulatory or lung failure that } \\
\text { is associated with a serum creatinine level of } 1.5- \\
1.9 \mathrm{mg} / \mathrm{dL} \text { and/or hepatic encephalopathy grade } 1 \text { or } \\
\text { grade } 2 \\
\text { - Single brain failure with a serum creatinine level of } 1.5- \\
1.9 \mathrm{mg} / \mathrm{dL} \\
\text { ACLF grade } 2 \text { because } 28 \text {-day mortality is } 32 \% \text { in patients } \\
\text { with: } \\
\text { - Two organs failures } \\
\text { ACLF grade } 3 \text { because } 28 \text {-day mortality is } 77 \% \text { in patients } \\
\text { with: } \\
\text { - Three organ failures or more }\end{array}$ & $\begin{array}{l}\text { Absence of ACLF: } \\
\text { No organ failure } \\
\text { Presence of any single organ failure } \\
\text { Presence of ACLF (called here } \\
\text { infection-related ACLF) } \\
\text { Two organ failures or more }\end{array}$ & $\begin{array}{l}\text { ACLF is a syndrome characterised } \\
\text { by acute hepatic decompensation } \\
\text { resulting in liver failure (jaundice } \\
\text { and prolongation of the INR) and } \\
\text { one or more extrahepatic organ } \\
\text { failures that is associated with } \\
\text { increased mortality within a period } \\
\text { of } 28 \text { days and up to } 3 \text { months from } \\
\text { onset }\end{array}$ \\
\hline
\end{tabular}




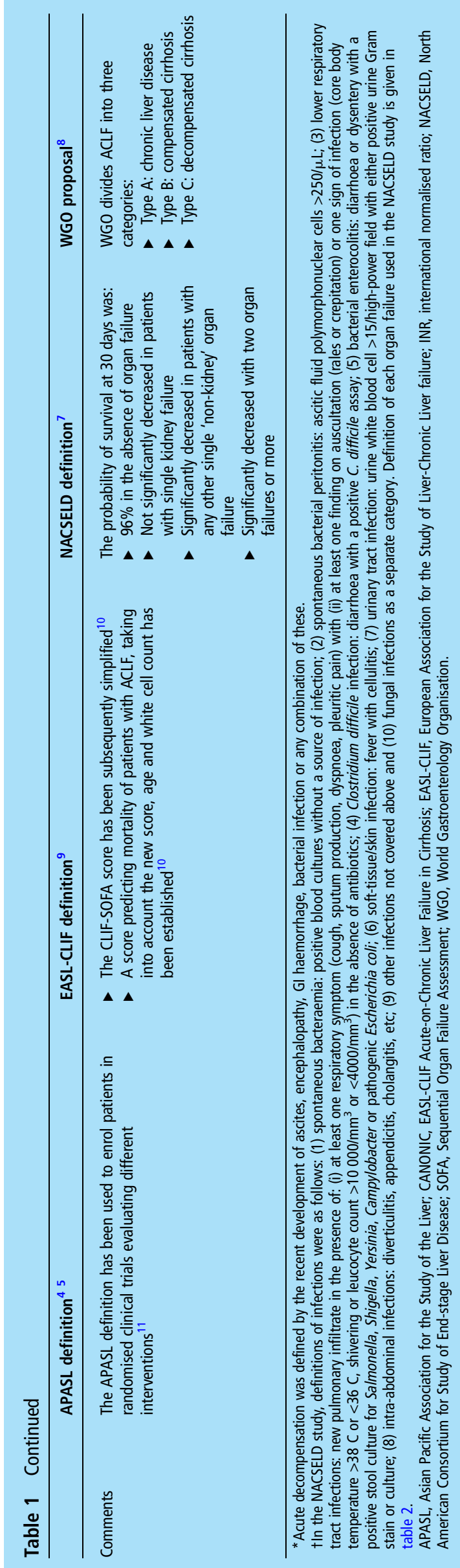

Underlying chronic liver disease and triggering factors

Prevalence of ACLF

The variety of definitions makes quite difficult to predict what would be an accurate proportion of patients with cirrhosis who would meet criteria for ACLF. Nevertheless, based on hospital registries it is reasonable to estimate that ACLF is present in between $24 \%$ and $40 \%$ of patients with cirrhosis admitted to the hospital. ${ }^{7}$ 12-15

Aetiology of chronic liver disease in ACLF

Adapted from Abbas and Shazi, ${ }^{16}$ table 3 summarises selected original publications examining the underlying chronic liver disease in populations with ACLF. Viral hepatitis, alcohol or a combination of both are the predominant causes of underlying chronic liver disease in ACLF in the world. The change in dietary patterns and lifestyle will likely lead to a shift on the ACLF predisposing disease and, as other areas in hepatology, it would not be surprising if non-alcoholic steatohepatitis took the lead in years to come. ${ }^{17}$

\section{Triggers of decompensation in ACLF}

The prevalence of potential triggers also varies by the area of the world. For example, in the CANONIC study, bacterial infections and alcoholism are the two major identifiable factors, compared with China, where relapse of hepatitis B was predominant followed by bacterial infections ${ }^{914}$ (table 4).

Despite exhaustive examination, in $20 \%-45 \%$ of cases, the trigger remains unknown. The type of injury also seems to influence ACLF outcomes as recently published by Shi et al. ${ }^{14}$ Four hundred and five Chinese patients who met CANONIC criteria were divided in hepatic-ACLF trigger, that is, driven by primarily liver toxins (alcohol, hepatitis) vs extrahepatic-ACLF (eg, infections). Both groups had high 28 -day mortality $(48.3 \%$ vs $50.7 \%)$, but this difference changed after 90 days $(58.9 \%$ vs $68.3 \%)$ and 1 -year mortality (63.9\% vs $74.6 \%)$.

\section{Organ failure}

In the CANONIC study, the kidneys were the most common affected organs (55.8\% of patients), followed by the liver $(43.6 \%$ of patients), coagulation (27.7\% of patients), the brain ( $24.1 \%$ of patients), circulation (16.8\% of patients) and the lungs $(9.2 \%$ of patients). ${ }^{9}$ In the NACSELD study, $55.7 \%$ had grade III-IV HE, $17.6 \%$ developed shock, $15.1 \%$ required renal replacement therapy and $15.8 \%$ required mechanical ventilation. ${ }^{7}$ The proportions in the American study are lower compared with the European one, but are likely a reflection of a broader inclusion of patients with cirrhosis in the CANONIC study.

\section{PATHOPHYSIOLOGY OF SYSTEMIC INFLAMMATION IN ACLF}

Systemic inflammation is a hallmark of ACLF; ${ }^{9}{ }^{24}$ white cell count and plasma levels of $\mathrm{C}$ reactive protein (CRP) and pro-inflammatory molecules such as interleukin (IL)-6, IL-1 $\beta$, IL-8 are higher in patients with ACLF than in those without. ${ }^{25}{ }^{26}$ Currently, there is no mouse model of ACLF, this is why results obtained in translational studies performed in patients are important to consider. Before commenting on inflammation in the context of ACLF, it is important to have in mind some general information on the inflammatory process.

\section{General principles of the inflammatory response}

The inflammatory response develops when inducers of inflammation are recognised by sensors that engage effectors of the response. ${ }^{27-29}$ 
Table 2 Examples of available definitions of organ failures used in patients with cirrhosis

\begin{tabular}{|c|c|c|c|}
\hline $\begin{array}{l}\text { Failing } \\
\text { organ }\end{array}$ & $\begin{array}{l}\text { Asian Pacific Association for the } \\
\text { Study of the Liver organ failures } \\
\text { definition }(4,5)\end{array}$ & $\begin{array}{l}\text { European Association for the Study of } \\
\text { Liver-Chronic Liver failure organ failures } \\
\text { definition (9) }\end{array}$ & $\begin{array}{l}\text { North American Consortium for Study of End-stage Liver } \\
\text { Disease organ failures definition (7) }\end{array}$ \\
\hline Liver & Total bilirubin $\geq 5 \mathrm{mg} / \mathrm{dL}$ and INR $\geq 1.5$ & Bilirubin level of $>12 \mathrm{mg} / \mathrm{dL}$ & - \\
\hline Kidney & Acute Kidney Injury Network criteria & $\begin{array}{l}\text { Creatinine level of } \geq 2.0 \mathrm{mg} / \mathrm{dL} \text { or renal } \\
\text { replacement }\end{array}$ & Need for dialysis or other forms of renal replacement therapy \\
\hline Brain & $\begin{array}{l}\text { West-Haven hepatic encephalopathy } \\
\text { grade } 3-4\end{array}$ & $\begin{array}{l}\text { West-Haven hepatic encephalopathy grade } \\
3-4\end{array}$ & West-Haven hepatic encephalopathy grade $3-4$ \\
\hline Coagulation & INR $\geq 1.5$ & INR $\geq 2.5$ & - \\
\hline Circulation & - & $\begin{array}{l}\text { Use of vasopressor (terlipressin and/or } \\
\text { catecholamines) }\end{array}$ & $\begin{array}{l}\text { Presence of shock defined by mean arterial pressure }<60 \mathrm{~mm} \mathrm{Hg} \text { or } \\
\text { a reduction of } 40 \mathrm{~mm} \mathrm{Hg} \text { in systolic blood pressure from baseline, } \\
\text { despite adequate fluid resuscitation and cardiac output }\end{array}$ \\
\hline Respiration & & $\begin{array}{l}\mathrm{PaO}_{2} / \mathrm{FiO}_{2} \text { of } \leq 200 \text { or } \mathrm{SpO}_{2} / \mathrm{FiO}_{2} \text { of } \leq 214 \\
\text { or need for mechanical ventilation }\end{array}$ & Need for mechanical ventilation \\
\hline
\end{tabular}

Inducers of inflammation

Inducers of inflammation are either exogenous or endogenous. $^{27-29}$ Among exogenous inducers, only microbial inducers will be discussed because the others have been already reviewed ${ }^{28}$ and are beyond the scope of ACLF.

\section{Microbial inducers}

\section{Bacterial inducers}

Bacteria trigger inflammation by using two distinct classes of molecules: pathogen-associated molecular patterns (PAMPs) $)^{27-31}$ and virulence factors. ${ }^{27-29}$ PAMPs are unique molecular signatures that are recognised via dedicated receptors called pattern-recognition receptors (PRRs), a process called structural feature recognition (figure 1$)^{32}$ (table 5).

PRRs are expressed in innate immune cells and epithelial cells. ${ }^{32}$ PRRs include toll-like receptors (TLRs), nucleotidebinding oligomerisation domain-like receptors (NLRs), retinoic acid-inducible gene (RIG)-I (a member of the RIG-I-like receptor (RLR) family), cytosolic DNA sensors, inflammatory caspase-4/5 in humans and caspase- 11 in mice. ${ }^{27}{ }^{29-31}$ PRR engagement by PAMPs stimulates intracellular signalling cascades that activate transcription factors, for example, nuclear factor- $\mathrm{\kappa B} .{ }^{30}{ }^{31}$ PRR-activated transcription factors induce a broad variety of genes encoding molecules involved in inflammation such as cytokines, chemokines, among others. ${ }^{30} 31$

Virulence factors represent the second class of bacterial inducers of inflammation. ${ }^{27-29} 32$ These factors are generally not recognised by dedicated receptors but detected through the effects of their activity (a process called functional feature recognition) (figure 1). ${ }^{28} 32$ At the site of infection, the detection of the presence of the bacteria via the recognition of structural and functional bacterial features is thought to induce complementary responses aiming to eliminate the invading microbe. ${ }^{32}$

\section{Other microbes}

Viruses or fungi are recognised by different PRRs (table 5). For example, viral nucleic acids can be recognised by endosomal TLRs, cytosolic receptors (RLRs or DNA sensors). Fungi express PAMPs that are detected by C-type lectin receptors. Like detection of bacterial PAMPs, that of viral or fungal PAMPs can trigger inflammation (figure 1).

\section{Endogenous inducers}

Endogenous inducers are released by necrotic cells or as a result of extracellular matrix breakdown. ${ }^{28} 33$ These endogenous inducers are called danger-associated molecular patterns (DAMPs) ${ }^{33}$ because they alert the host's immune system about the presence of a serious tissue injury. DAMPs are recognised by receptors of the host (table 6) and this recognition induces sterile inflammation.

\section{Outcomes of the inflammatory response}

In the context of bacterial infection, the inflammatory response is complex and generally involves the innate and adaptive

Table 3 Example of studies examining the underlying cause of chronic liver disease in acute-on-chronic liver failure (ACLF)

\begin{tabular}{|c|c|c|c|c|c|c|c|c|}
\hline First author, year (ref) & Country/region & ACLF definition & No & Viral, n (\%) & Alcohol, n (\%) & $\begin{array}{l}\text { Alcohol+viral } \\
\text { n (\%) }\end{array}$ & Cryptogenic, n (\%) & Miscellaneous, n (\%) \\
\hline $\mathrm{Du}, 2005^{18}$ & China & $N / R$ & 650 & $524(81)$ & & $80(12)$ & & $46(7)$ \\
\hline Xia, $2013^{19}$ & China & \# & 857 & $602(70)$ & $56(7)$ & $149(17)$ & & $50(6)$ \\
\hline Kedarisetty, $2014^{20}$ & Asia Pacific & APASL & 1363 & $335(25)$ & $645(47)$ & & $220(20)$ & $106(8)$ \\
\hline Shi, $2015^{21}$ & China & APASL & 540 & $405(75)$ & $30(6)$ & $62(11)$ & $28(5)$ & $15(3)$ \\
\hline Wehler, $2001^{22}$ & Germany & SOFA & 143 & $20(14)$ & $108(75)$ & & $5(4)$ & $10(7)$ \\
\hline Cholongitas, $2006^{23}$ & UK & APASL & 312 & 54 (17) & $203(65)$ & & $14(5)$ & $41(13)$ \\
\hline Moreau, $2013^{9}$ & Europe & CANONIC & 303 & $38(12)$ & $170(56)$ & $27(9)$ & & $68(22)$ \\
\hline Bajaj, $2014^{7}$ & USA & NACSELD & 507 & $124(25)$ & $74(15)$ & $138(27)$ & $78(15)$ & $93(18)$ \\
\hline
\end{tabular}

(\#) (1) acute deterioration of pre-existing chronic liver disease; (2) extreme fatigue with severe digestive symptoms, such as obvious anorexia, abdominal distension, nausea and vomiting; (3) progressively worsening jaundice within a short period (serum total bilirubin level $\geq 10 \mathrm{mg} / \mathrm{dL}$ or a daily elevation $\geq 1 \mathrm{mg} / \mathrm{dL}$ ); (4) an obvious haemorrhagic tendency with prothrombin activity $\leq 40 \%$ (approximate prothrombin time $\geq 18.3 \mathrm{~s}$, international normalised ratio $>1.50$ ).

APASL, Asian Pacific Association for the Study of the Liver; CANONIC, EASL-CLIF Acute-on-Chronic Liver Failure in Cirrhosis; NACSELD, North American Consortium for Study of End-stage Liver Disease; SOFA, Sequential Organ Failure Assessment. 
Table 4 Reported triggers of acute-on-chronic liver failure, number $(\%)$

\begin{tabular}{lcc}
\hline & $\begin{array}{c}\text { CANONIC } \\
\mathbf{n}=303,(9)\end{array}$ & $\begin{array}{c}\text { Shi } \text { et al } \\
\mathbf{n}=405,(14)\end{array}$ \\
\hline Exacerbation hepatitis B & - & $145(35.8)$ \\
Bacterial infection & $98(32.6)$ & $113(27.9)$ \\
Gl haemorrhage & $40(13.2)$ & $40(9.8)$ \\
Active alcoholism within the past 3 months & $69(24.5)$ & $25(6.1)$ \\
Other (TIPSS, surgery, large volume paracentesis & $25(8.6)$ & $9(2)$ \\
without albumin, hepatitis, alcoholic hepatitis) & & \\
Not identifiable & $126(43.6)$ & $83(20.4)$ \\
More than one & $39(13.5)$ & $36(8.9)$ \\
\hline
\end{tabular}

CANONIC, EASL-CLIF Acute-on-Chronic Liver Failure in Cirrhosis; TIPSS, transjugular intrahepatic portosystemic shunt.

immune systems. ${ }^{32}$ The primary purpose of the inflammatory response to bacterial infection is to promote host resistance by reducing bacterial burden. When local defences are ineffective in containing infection, the immune system stimulates a systemic response to fight against the spreading microbe. For example, IL-6 and IL-1 $\beta$ (among others) induce the production of acutephase response proteins, including CRP, serum amyloid proteins and complement proteins to stimulate bacterial clearance by phagocytes. $^{34}$ In some cases, the early systemic inflammatory response to bacteria can be excessive and cause organ damage (a process called immunopathology) decreasing short-term survival. In the context of sterile inflammation, the primary purpose of the inflammatory response is to promote tissue repair (figure 1 ). ${ }^{35}$ The tissue-repair response can involve specialised components of the innate and adaptive immunity, but does not lead to adaptive immunity. ${ }^{32} 35$ In some cases, the sterile inflammatory response can be excessive and become systemic causing severe multiorgan damage. ${ }^{36}$

The excessive inflammatory response to PAMPs or DAMPs can be due to host genetic factors. In the general population, in the context of infections, single nucleotide polymorphisms (SNPs) related to genes encoding molecules involved in the immune response have been shown to be associated with the risk of severe inflammation. For example, significant polymorphisms have been found in CD14 (encoding a cell surface receptor that contributes with TLR4 and MD2 to recognition of lipopolysaccharide (LPS)), TNF (encoding tumour necrosis factor (TNF)- $\alpha$ ), LTA (encoding lymphotoxin- $\alpha$ ), TLRs (TLR1, TLR4, see table 5), TIRAP (encoding toll/IL-1 receptor domaincontaining adapter protein, transducing TLR4 signalling), MIF (encoding macrophage migration inhibitory factor), SERPINB2 (encoding plasminogen activator inhibitor 2), ADRB2 (encoding $\beta-2$ adrenergic receptor) (reviewed in ${ }^{37} 38$ ).

The severity of infection can also be related to pathogens (Gram-negative infections being more severe than Gram-positive
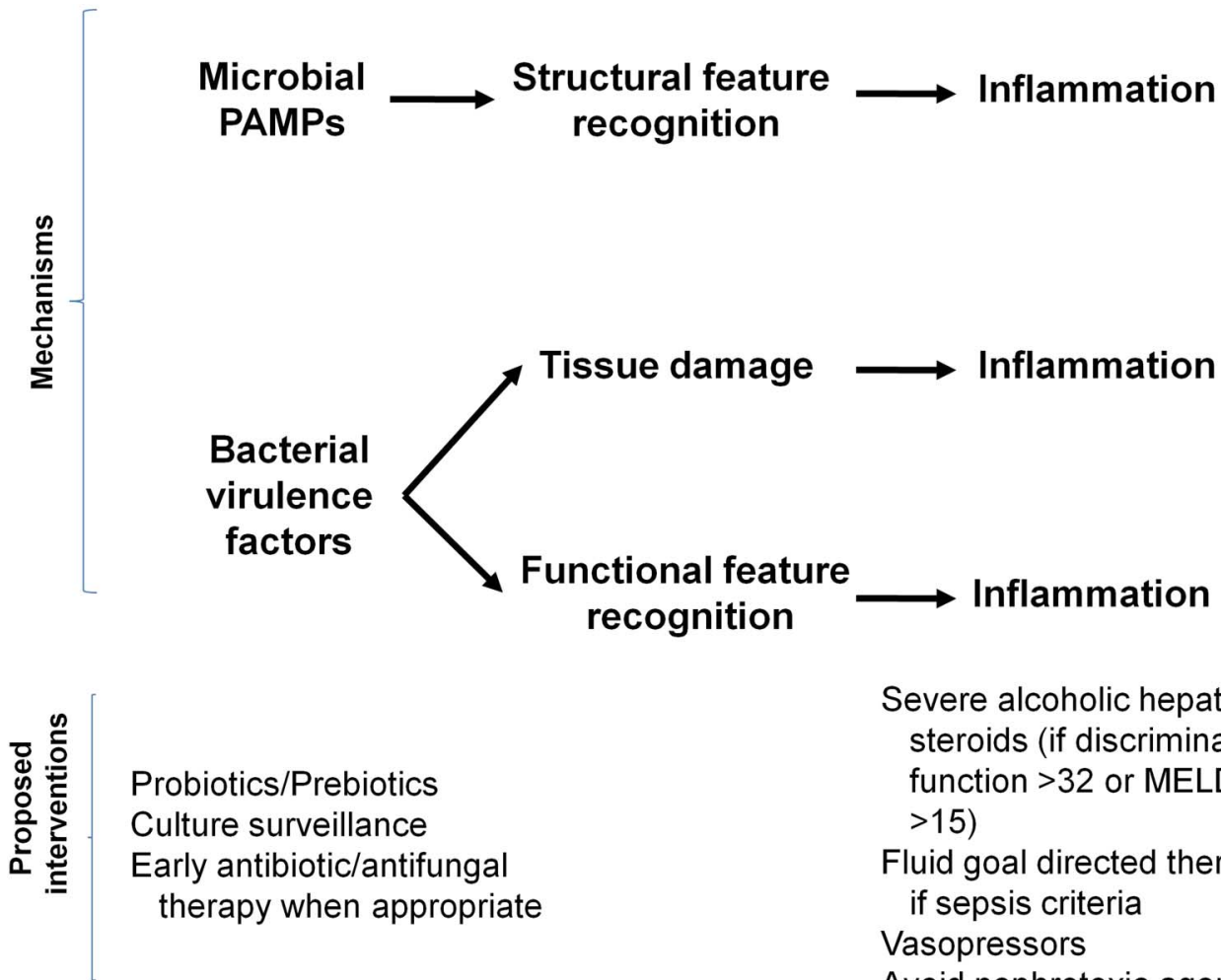
Severe alcoholic hepatitis: steroids (if discriminant function >32 or MELD $>15)$
Fluid goal directed therapy if sepsis criteria Vasopressors Avoid nephrotoxic agents

Figure 1 Inflammation caused by microbes. Top: Microbes (bacteria, viruses, fungi) induce inflammation via two classes of molecules: pathogen-associated molecular patterns (PAMPs) and virulence factors. Sensors of the innate immune system recognise the invading microbe via recognition of PAMPs, which are conserved molecular patterns (structural feature recognition). Sensors are known as pattern-recognition receptors. The second class of microbial inducers of inflammation includes a large number of virulence factors. Most of these factors are generally not recognised by dedicated receptors but can be sensed via the effects of their activity (functional feature recognition). For example, there are bacterial virulence factors which cause modifications and inactivation of host Rho GTPases and these alterations are sensed by the Pyrin inflammasome. Infection may be associated with tissue damage caused by the bacteria or by the immune response to bacteria. Tissue damage can induce inflammation which is committed to tissue repair (see text and reference ${ }^{32}$ ). Bottom: Proposed interventions. MELD, Model For End-Stage Liver Disease score. 
Table 5 Examples of PRRs, their ligands (PAMPs) and their origin

\begin{tabular}{|c|c|c|}
\hline PRR & PAMP & Origin \\
\hline \multicolumn{3}{|l|}{ TLRs } \\
\hline TLR1 & Triacylated lipopeptides & Bacteria \\
\hline TLR2 & Peptidoglycan & Bacteria, viruses \\
\hline TLR3 & Double-stranded RNA & Virus \\
\hline TLR4 & Lipopolysaccharides & Bacteria \\
\hline TLR5 & Flagellin & Bacteria \\
\hline TLR6 & Diacylated lipopeptides & Bacteria, viruses \\
\hline TLR7 (human TLR8) & Single-stranded RNA & Virus, bacteria \\
\hline TLR9 & CpG-DNA & Virus, bacteria \\
\hline \multicolumn{3}{|l|}{ NLR } \\
\hline NOD1 & $\begin{array}{l}\gamma \text {-D-Glutamyl-mesodiaminopimelic } \\
\text { acid }\end{array}$ & Bacteria \\
\hline NOD2 & Muramyl dipeptide & Bacteria \\
\hline \multicolumn{3}{|l|}{ RIG-I-like receptors } \\
\hline DDX58 (alias: RIG-I) & Short double-stranded RNA & Viruses \\
\hline IFIH1 (MDA5) & Long double-stranded RNA & Viruses \\
\hline \multicolumn{3}{|l|}{ Cytosolic DNA receptors } \\
\hline $\begin{array}{l}\text { AIM2 } \\
\text { IFI16 }\end{array}$ & Double-stranded DNA & Virus, bacteria \\
\hline $\begin{array}{l}\text { ZBP1 } \\
\text { MB21D1 (alias cGAS) }\end{array}$ & & \\
\hline \multicolumn{3}{|l|}{ C-type lectin receptors } \\
\hline Dectin-1 & $\beta$-Glucan & Fungi \\
\hline Dectin-1 & $\beta$-Glucan & Fungi \\
\hline MINCLE & SAP130 & Fungi \\
\hline \multicolumn{3}{|c|}{$\begin{array}{l}\text { AIM2, absent in melanoma 2; cGAS, cyclic GMP-AMP synthase; CpG-DNA, DNA } \\
\text { containing the unmethylated phosphate-guanine (CpG) dideoxynucleotide motif; } \\
\text { IFI16, interferon, gamma-inducible protein 16; MINCLE, macrophage inducible C-type } \\
\text { lectin; NLR, NOD-like receptor; NOD, nucleotide-binding oligomerisation domain; } \\
\text { PAMP, pathogen-associated molecular patterns; PRR, pattern recognition receptor; } \\
\text { RIG-I, retinoic acid-inducible gene I; ZBP1, Z-DNA binding protein 1, MB21D1, } \\
\text { Mab-21 domain containing 1; TLR, toll-like receptor. }\end{array}$} \\
\hline
\end{tabular}

infections) or to the site of infection (intra-abdominal sites having the highest risk of death and urinary the lowest). ${ }^{38}$ However, the role of excessive inflammation in the higher severity of infections, depending on the pathogen or site of infection, is unclear.

\section{ACLF with identified inducers of inflammation}

Sepsis-induced ACLF

Systemic inflammation and the development of OFs are attributed to bacterial infection in approximately $30 \%$ of patients with ACLF. ${ }^{9}$ These patients have sepsis-induced ACLF. The most common infection causing sepsis-induced ACLF is spontaneous bacterial peritonitis (SBP). ${ }^{9} \mathrm{SBP}$ is a paradigm in that it is often caused by Gram-negative bacteria that have migrated from the intestinal lumen to ascitic fluid via the systemic circulation.

During the acute phase bacterial infection, patients with cirrhosis have higher plasma levels of pro-inflammatory cytokines (TNF- $\alpha$ and IL-6) than patients without cirrhosis. ${ }^{39}$ Among patients with SBP, those who develop kidney failure have higher plasma TNF- $\alpha$ and IL- 6 than those who do not develop this complication. ${ }^{40}$ Mortality related to bacterial sepsis is greater in patients with cirrhosis than in those without. ${ }^{30}$ Interestingly, cirrhotic rats challenged with LPS (a bacterial PAMP recognised by the PRR (TLR4)) exhibit excessive systemic inflammation, severe acute liver injury and early mortality relative to noncirrhotic animals (reviewed $\mathrm{in}^{27}$ ). Together these results suggest the existence of an excessive inflammatory response to bacteria in cirrhosis. However, little is known about the underlying
Table 6 Examples of DAMPs and their receptors

\begin{tabular}{|c|c|}
\hline DAMP & Receptor \\
\hline \multicolumn{2}{|l|}{ Released by necrotic cells } \\
\hline ATP & Purinoceptors \\
\hline Monosodium urate & $\begin{array}{l}\text { NACHT, LRR and PYD domains containing } \\
\text { protein } 3 \text { (also known as cryopyrin; encoded } \\
\text { by NLRP3, alias NALP3) }\end{array}$ \\
\hline \multicolumn{2}{|l|}{ Nuclear DAMPs } \\
\hline $\begin{array}{l}\text { High-mobility group protein } 1 \\
\text { (encoded by HMGB1) }\end{array}$ & $\begin{array}{l}\text { Advanced glycosylation end } \\
\text { product-specific receptor (encoded by } \\
\text { AGER also known as } R A G E) \\
\text { TLRs }\end{array}$ \\
\hline $\begin{array}{l}\text { Histone deacetylase complex } \\
\text { subunit SAP130 }\end{array}$ & $\begin{array}{l}\text { C-type lectin domain family } 4 \text { member } \mathrm{E} \\
\text { (encoded by CLECSF9 also known as } \\
\text { MINCLE) }\end{array}$ \\
\hline Extracellular histones & Unknown \\
\hline $\begin{array}{l}\text { HSPs } \\
\text { HSP-60 }\end{array}$ & TLR2, TLR4 \\
\hline \multicolumn{2}{|l|}{ IL-1 family } \\
\hline IL-1 $\alpha$ & IL-1R-1 and IL-1RAcP \\
\hline IL-33 & $\begin{array}{l}\text { IL-1 receptor-like } 1 \text { (also known as protein } \\
\text { ST2) and IL-1RACP }\end{array}$ \\
\hline \multicolumn{2}{|l|}{ S100 calcium-binding protein family } \\
\hline S100A8, S100A9 & TLR4 \\
\hline $\mathrm{S} 100 \mathrm{~A} 12$ & AGER \\
\hline \multicolumn{2}{|l|}{ Mitochondrial DAMPs } \\
\hline Mitochondrial DNA & TLR9 \\
\hline $\mathrm{N}$-formylated peptides & Formyl peptide receptor \\
\hline Peroxiredoxins & TLR2, TLR4 \\
\hline \multicolumn{2}{|c|}{ Products of extracellular matrix breakdown } \\
\hline $\begin{array}{l}\text { Low-molecular weight } \\
\text { fragments of hyaluronic acid }\end{array}$ & TLR4 \\
\hline \multicolumn{2}{|c|}{$\begin{array}{l}\text { *Protein names used for DAMPs and receptors are official names provided by } \\
\text { UniProtKB (http://www.uniprot.org); genes symbols are provided by Hugo Gene } \\
\text { Nomenclature Committee (http://www.genenames.org). } \\
\text { DAMP, danger-associated molecular pattern; HSP, heat shock protein; IL, interleukin; } \\
\text { IL-1R-1, IL-1 receptor type 1; IL-1RAcP, IL-1 receptor accessory protein; LRR, leucine- } \\
\text { rich repeats; MINCLE, macrophage inducible C-type lectin; NACHT, NAIP, CIITA, HET-E } \\
\text { and TP1; PYD, pyrin domain; TLR, toll-like receptor. }\end{array}$} \\
\hline
\end{tabular}

mechanisms that explain the excessive inflammation in cirrhosis. There are studies that focused on the ex vivo response to LPS in freshly isolated monocytes or peripheral blood mononuclear cells from patients with cirrhosis and without cirrhosis. These studies suggest an excessive innate immune response to LPS related to defective negative feedback mechanisms of the TLR4-mediated response. These defects involved the phosphoinositide $3 \mathrm{kinase} / \mathrm{AKT} / \mathrm{glycogen}$ synthase kinase pathway as well as the induction of IL1 receptor associated kinase M (reviewed $\mathrm{in}^{27}$ ). There are also studies showing that single nucleotide polymorphism (SNP) is some selected genes involved in the innate immune response were associated with increased risk of infection and mortality (reviewed in $^{29}$ ). However, nothing is known about the mechanisms by which these SNPs might interfere with the immune response to bacteria. Moreover, the association of these SNPs with patients' outcome needs to be confirmed by using genome-wide association studies in a large series of patients with cirrhosis.

\section{Severe alcoholic hepatitis}

Severe alcoholic hepatitis (SAH) represents approximately 25\% of the cases of ACLF. ${ }^{9}$ Severity is related to the development of OFs. ${ }^{9}$ Systemic inflammation develops in patients with SAH and correlates with the outcome suggesting a role of inflammation in 
the development of OFs. ${ }^{41}$ Systemic inflammation can be caused by bacterial infection which is present in $\sim 30 \%$ of patients admitted to the hospital for SAH. ${ }^{42}$ Excessive alcohol consumption is associated with intestinal dysbiosis and increased intestinal permeability, which favour translocation of viable bacteria. ${ }^{27}$ This may explain why SBP is the most common infection at admission of patients with $\mathrm{SAH} .{ }^{42}$ However, systemic inflammation is also observed in patients with $\mathrm{SAH}$ without clinically detectable bacterial infection. ${ }^{9} 41$ In this context, the mechanisms explaining systemic inflammation are unclear. Alterations in the gut microbiome and intestinal permeability may favour the translocation of bacterial PAMPs (eg, LPS) as suggested by the findings of increased systemic LPS levels in patients with SAH. ${ }^{41}$ Therefore, increased circulating levels of PAMPs may engage their cognate PRRs and stimulate inflammation in the liver and the systemic compartment. Moreover, in patients with SAH, higher the LPS levels, higher is the intensity of the systemic inflammatory response. ${ }^{41}$ Accordingly, in these patients, LPS-driven inflammation could play a major role in the development of OFs and subsequent death. ${ }^{41}$ On the other hand, systemic inflammation may originate in the diseased livers from patients with SAH. Indeed, several pro-inflammatory molecules are overexpressed in livers with SAH relative to livers without $\mathrm{SAH},{ }^{43}$ suggesting that these molecules may spill-over the liver and reach systemic circulation. Future studies should address the PAMP-induced and liverrelated theories for systemic inflammation in $\mathrm{SAH}$.

\section{ACLF with no obvious trigger}

About $40 \%-50 \%$ of patients with ACLF have systemic inflammation for which there are no clinically identifiable triggers. ${ }^{9}$ Three hypotheses may explain the induction of inflammation in this context (reviewed in ${ }^{27}$ ). In sum, the first hypothesis suggests that metabolites produced by gut bacteria may reach the systemic compartment and stimulate inflammation. This hypothesis is based on the following clues: (1) gut dysbiosis has been shown in patients with cirrhosis and (2) gut bacteria produce metabolites that may interact with the inflammatory response of the non-cirrhotic host. The second bypothesis for 'unexplained' inflammation in ACLF involves translocation of bacterial PAMPs and the third one suggests an action of DAMPs. High-throughput techniques investigating metabolome, lipidome, glycome and metagenome would be useful to address these hypotheses.

\section{Remaining questions}

Although excessive systemic inflammation is believed to be the driver for the development of OFs, one cannot exclude that other mechanisms may contribute to this development. For example, there are studies under non-cirrhotic conditions, showing that severe outcome of bacterial infection can be caused by failure of mechanisms that are intrinsic to tissues and protect them against the noxious effects caused by the microbe itself or the host's immune response. ${ }^{44-46}$ In other words, infection may be severe because of failed disease tolerance (ie, endurance). ${ }^{44-46}$ There may be differences in disease tolerance among patients with ACLF. Thus, for any given level of systemic inflammation, patients with ACLF who had prior episodes of decompensation of liver disease were less severe than those who did not have prior episodes of decompensation. ${ }^{9}$ Patients with a prior history of liver decompensation may have acquired an increased tolerance capacity that protected them when exposed to new noxious stimuli.
It has recently been shown that patients with ACLF had both marked systemic inflammation (ie, increased plasma cytokines levels) and some features of immune suppression. ${ }^{24}$ Indeed, these patients had increased frequency of circulating CD14-positive monocytes that overexpressed the protein MER and exhibited a decreased ex vivo response to LPS. ${ }^{24}$ These results were expected because MER receptors are members of the Tyro3, AXL oncogene, MER (TAM) family receptor-tyrosine kinases, which are known to inhibit TLR4 signalling. ${ }^{47}$ Another study found that plasma from patients with ACLF had increased levels of prostaglandin E2 (PGE2), which may inhibit macrophage cytokine production in response to LPS. ${ }^{48}$ In addition, PGE2 was found to decrease the macrophage ability to kill bacteria. ${ }^{48}$ Together, these findings suggest that, in patients with ACLF, an immune suppression of monocytes/macrophages develops in parallel to the systemic inflammatory response. The suppression of monocyte/ macrophage functions would explain the high risk of nosocomial infections in patients with ACLF. It has been suggested that, in patients with ACLF, immune suppression might be a regulation whose purpose is to limit responses of effector monocytes to elevated amount of extracellular stimuli (PAMPs, DAMPs, soluble signals, cytokines, chemokines). ${ }^{27}{ }^{49}$ However, there is currently no evidence supporting this hypothesis. Future studies should investigate whether the development of excessive systemic inflammation and that of immune suppression are related to each other in patients with ACLF.

\section{DIAGNOSIS}

Among all operational definitions of ACLF (table 1), the definition and diagnostic criteria proposed by the EASL-CLIF Consortium represent the first one based on large prospective data including all patients with cirrhosis, regardless of the presence of infection, from a multicentre European prospective cohort, the CANONIC study. According to this cohort, ACLF is defined as acute decompensation (AD) of cirrhosis associated with $\mathrm{OF}$ and high short-term mortality (28-day mortality $\geq 15 \%){ }^{9}$ The SOFA score was the model used for the diagnosis of OF, as it is a widely used method in critically ill patients and is superior to Model For End-Stage Liver Disease (MELD) score in predicting prognosis in patients with $\mathrm{AD}$ of cirrhosis associated with OFs. ${ }^{9} 50$ Considering that the components of SOFA score (liver, kidney, brain, coagulation, circulation and lungs) do not take into account specific characteristics of patients with cirrhosis, the method used for the diagnosis of ACLF was a modified version of SOFA score, called CLIF-SOFA score. This was later simplified in a new version called CLIF Consortium Organ Failure score (CLIF-C OFs) ${ }^{10}$ (table 7).

The presence and the number of OFs as assessed by the CLIF-SOFA or the CLIF-C OF scores were associated with 28-day and 90-day mortality. Moreover, some specific organ dysfunction such as kidney dysfunction and moderate HE, when associated with single OF, were also associated with prognosis. On this background, diagnostic criteria of ACLF were established according to the presence, type and number of OFs. Severity of ACLF was graded into different stages according to the number of OFs on ACLF grade 1 , grade 2 and grade $3^{9}$ (table 1, under EASL-CLIF column) and mortality correlates with ACLF severity (figure 2).

It should be noted that ACLF may occur both in patients with previously compensated or decompensated cirrhosis, and also in patients with underlying chronic liver disease without cirrhosis. In this context, the WGO proposed a further classification of ACLF into three groups, according to the underlying liver disease: type A ACLF (patients with underlying non-cirrhotic 
Table 7 CLIF Consortium Organ Failure Score: simplified version of the CLIF-SOFA score

\begin{tabular}{|c|c|c|c|c|}
\hline $\begin{array}{l}\text { Organ/ } \\
\text { system }\end{array}$ & Variable & Score $=1$ & Score $=2$ & Score $=3$ \\
\hline Liver & Bilirubin (mg/dL) & $<6$ & 6 to $\leq 12$ & $>12$ \\
\hline Kidney & Creatinine (mg/dL) & $<2$ & 2 to $<3.5$ & $\geq 3.5$ or RRT \\
\hline Brain & $\begin{array}{l}\text { Encephalopathy grade } \\
\text { (West-Haven) }\end{array}$ & 0 & $1-2$ & $3-4$ \\
\hline Coagulation & INR & $<2$ & 2 to $<2.5$ & $\geq 2.5$ \\
\hline Circulation & MAP (mm Hg) & $\geq 70$ & $<70$ & Vasopressors \\
\hline Respiratory & $\mathrm{PaO}_{2} / \mathrm{FiO}_{2}$ or $\mathrm{SpO}_{2} / \mathrm{FiO}_{2}$ & $\begin{array}{l}>300 \\
>357\end{array}$ & $\begin{array}{l}\leq 300 \text { and } \\
>200 \\
>214 \text { and } \\
\leq 357\end{array}$ & $\begin{array}{l}\leq 200 \\
\leq 214\end{array}$ \\
\hline \multicolumn{5}{|c|}{$\begin{array}{l}\text { Highlighted areas indicate the definition of each organ failure. } \\
\mathrm{CLIF} \text {, chronic liver failure; } \mathrm{FiO}_{2} \text {, fraction of inspired oxygen; INR, international } \\
\text { normalised ratio; } \mathrm{MAP} \text {, mean arterial pressure; } \mathrm{PaO}_{2} \text {, partial pressure of arterial } \\
\text { oxygen; RRT, renal replacement therapy; SOFA, Sequential Organ Failure Assessment; } \\
\mathrm{SpO}_{2} \text {, pulse oxymetric saturation. }\end{array}$} \\
\hline
\end{tabular}

chronic liver disease), type B ACLF (patients with previous compensated cirrhosis) and type C ACLF (patients with previous decompensated cirrhosis). ${ }^{8}$ Type A ACLF is that occurring in patients with non-cirrhotic chronic liver disease and it may have a clinical presentation similar to that of acute or subacute liver failure. Considering that acute or reactivation of viral hepatitis is the most common precipitating event in the East, ${ }^{5}$ type A ACLF would preferentially be more frequent in Eastern countries. Using the CANONIC study as a reference, type A patients with ACLF would need to have at least (1) single kidney failure; (2) single liver, coagulation, circulatory or lung failure that is associated with a serum creatinine level of $1.5-1.9 \mathrm{mg} / \mathrm{dL}$ and/ or HE grade 1 or grade 2 or (3) single brain failure with a serum creatinine level of $1.5-1.9 \mathrm{mg} / \mathrm{dL}$ (table 7 ). The definition of ACLF type A needs further validation in prospectively collected cohorts to establish whether this patient population indeed has a mortality rate $\geq 15 \%$ after 28 days. Type B or C ACLF are those occurring in patients with underlying cirrhosis. Interesting data from the CANONIC study show that patients with previous decompensation (type C ACLF) had a significantly lower mortality compared with those patients without previous decompensation (type B ACLF). ${ }^{9}$ The reason for this difference needs further investigation, but it could be related to a decrease in the capacity of tolerance of vital organs to inflammatory response in patients without previous decompensations.

\section{NATURAL HISTORY AND ASSESSMENT OF PROGNOSIS IN PATIENTS WITH ACLF ACLF grade predicts mortality}

As described above, ACLF is associated with high short-term mortality. ACLF grade at diagnosis is associated with short-term prognosis, with patients with ACLF grade 3 showing the worst prognosis compared with that of patients with ACLF grade 1 and 2. Data from the CANONIC study showed overall 28-day mortality of $33 \%$ of all cases of ACLF, and specific 28 -day mortality rates in patients with ACLF grade 1, 2 and 3 was $22 \%$, $32 \%$ and $73 \%$, respectively ${ }^{9}$ (figure 2 ).

Therefore, it is very important to stratify patients according to prognosis, in order to monitor treatment responsiveness, determine emergency for transplantation, decide allocation in the intensive care unit (ICU) and also to have a rational basis to decide futility.

\section{CLIF-C: a liver-specific score to predict outcomes in ACLF}

Until recently, MELD score, MELD-Na and Child-PughTurcotte scores, the conventional scoring systems to assess prognosis in patients with cirrhosis, were the only available methods to evaluate prognosis in patients with ACLF. However, these scores have limited accuracy to predict prognosis in ACLF as they do not consider the existence of all the potential extrahepatic OFs, which have an important impact in the prognosis of these patients. As described above, the CANONIC study developed the CLIF SOFA score, and its simplified version CLIF-C OFs, which were found to be useful to diagnose ACLF according to the number and type of OFs. Besides being useful to determine the presence or absence of ACLF, CLIF SOFA and CLIF-C OF score were also found to be associated with prognosis. $^{9}{ }^{10}$ The performance of CLIF-C OFs in predicting shortterm mortality was similar to that of CLIF-SOFA score and slightly but significantly superior to MELD, MELD-Na and Child-Pugh-Turcotte scores. ${ }^{10}$
Figure 2 Relationship between organ failure and mortality in acute-on-chronic liver failure (ACLF). Twenty-eight-day mortality rates of patients with decompensated cirrhosis with (red bars) and without (green bars) ACLF according to the diagnostic criteria proposed in the CANONIC study. ${ }^{9}$ Patients are divided into the following categories: patients with no organ failure (OF); patients with a single non-kidney organ failure without kidney dysfunction (KD; a serum creatinine level of $1.5-1.9 \mathrm{mg} / \mathrm{dL}$ ) or brain dysfunction (BD; grade 1-2 hepatic encephalopathy); patients with a single kidney failure; patients with a single non-kidney organ failure with $\mathrm{KD}$ and/or $\mathrm{BD}$; patients with two organ failures and patients with three or more organ failures. Adapted with permission from Arroyo et al..$^{27}$

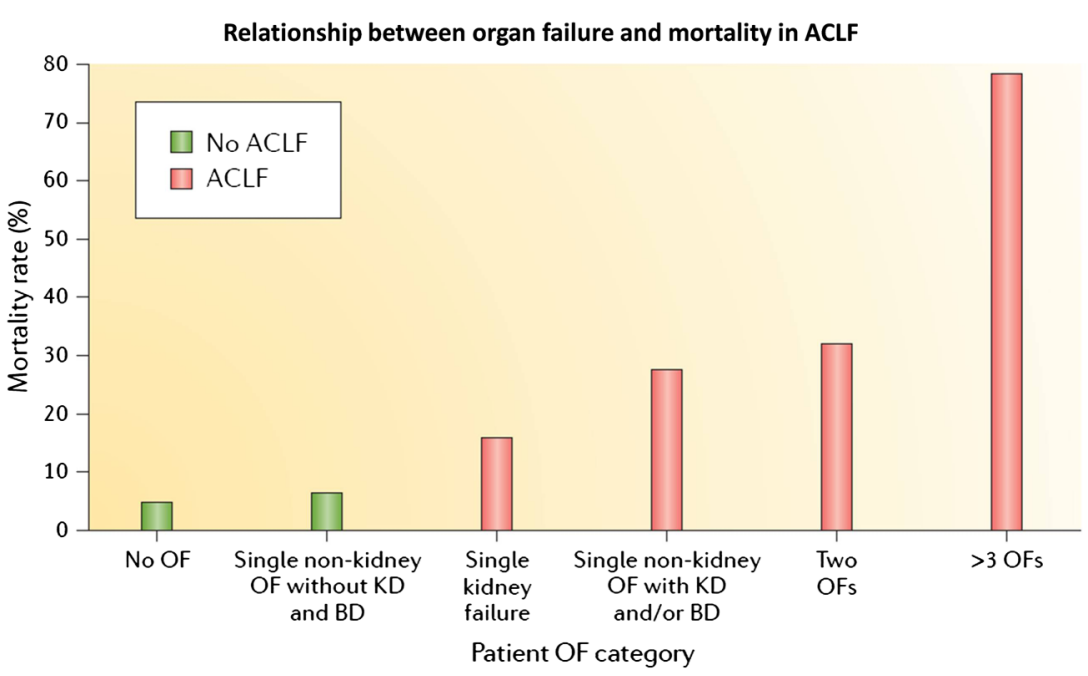

Hernaez R, et al. Gut 2017;66:541-553. doi:10.1136/gutjnl-2016-312670 
A recent study also based on the CANONIC study population, developed and independently validated a new scoring system with higher prognostic accuracy than conventional measures (MELD, MELD-Na and Child-Pugh-Turcotte scores) and also than CLIF-SOFA score. This is the so-called CLIF-C ACLF score. In order to build this score, CLIF-C OFs was combined with other two baseline variables that were selected as the best predictors of mortality: age and log-transformed white blood cell (WBC) count. CLIF-C ACLF score is calculated by the following equation: CLIF-C ACLFs $=10 \times(0.33 \times$ CLIF-C OFs $+0.04 \times$ age $+0.63 \times \ln ($ WBC count $)-2)$ and the final score ranges from 0 to $100 .^{10}$ This score can be easily calculated in the EF-CLIF website: http://www.efclif.com.

CLIF-C ACLF score showed a significantly higher predictive accuracy than MELD, MELD-Na and Child-Pugh-Turcotte score at all main time points after ACLF diagnosis (28, 90, 180 and 365 days). As compared with MELD, MELD-Na and Child-Pugh-Turcotte scores, the area under the receiver operating curve estimated for the CLIF-C ACLF score to predict 28-day and 90-day mortality were significantly higher and indicated a $7 \%-11 \%$ improvement in the discrimination ability ${ }^{10}$ (figure 3).

\section{ACLF is a dynamic process but final outcome can be predicted at day 7}

When evaluating prognosis in patients with ACLF, it should be noted that this is a dynamic syndrome that may improve or worsen during hospitalisation. Therefore, the ideal scoring system should be able to reflect the dynamic nature of the disease and the responsiveness to medical treatment. In this context, a recent study performed in the cohort of patients from the CANONIC study investigated the clinical course of ACLF and the predictors of course severity and mortality, showing interesting results. ${ }^{51}$ Overall, ACLF resolved or improved in $49 \%$ of patients, had a steady or fluctuating course in $30 \%$ and worsened in the remaining $20 \%$. However, resolution rate depended on the initial ACLF grade. While ACLF resolved in $55 \%$ of patients with ACLF grade 1, it only resolved in $15 \%$ of patients with ACLF grade 3 . An interesting finding of this study is that although the ACLF grade at diagnosis correlates with prognosis, the clinical course of the syndrome during hospitalisation was the most important determinant of short-term mortality. The majority of patients achieved their final grade of ACLF within the first week; therefore, the assessment of ACLF grade at days 3-7 after diagnosis predicted 28-day and 90-day mortality more accurately than ACLF grade at diagnosis. ${ }^{51}$ In keeping with these findings, when the previously described CLIF-C ACLF score was computed at 48 hours, 3-7 days and 8-15 days after the diagnosis of ACLF, the predictive accuracy of 28-day mortality was significantly better than when the score was calculated at the diagnosis of the syndrome. $^{10}$

Considering the newly defined scoring systems and recent data indicating that sequential assessment of prognosis seems to have higher accuracy than prognosis evaluated at the diagnosis of ACLF, stepwise algorithms have been proposed to assess prognosis and help decision making in patients with cirrhosis and ACLF. In summary, it is suggested that when a patient is admitted to hospital with AD of cirrhosis, CLIF-C OF score should be applied. This score will divide patients according to the presence or absence of ACLF. If ACLF is diagnosed, prognosis should be assessed by the CLIF-C ACLF score which should be calculated at the diagnosis of the syndrome and also 3-7 days after admission ${ }^{51}$ (figure 4).

\section{MANAGEMENT OF ACLF}

\section{General management}

Currently, there is no specific effective treatment available for patients with ACLF, and therefore treatment is based on organ support and treatment of associated complications.

When ACLF is associated with a precipitating factor (ie, bacterial infections, GI bleeding, alcoholism, drug toxicity), early identification and treatment of the precipitating factor are essential. However, this may not prevent the development or worsening of the syndrome. In addition, in up to $40 \%$ of patients a precipitating factor may not be identified. Moreover, available data suggest that although the precipitating factor may be the trigger of ACLF, it may not be an essential predictor of prognosis. ${ }^{9}$ Overall, patients with ACLF should be considered to be admitted to the ICU and should be preferably managed in a
Figure 3 Comparison of the area under the receiver operating curves (AUROCs) to predict 28-day (panel A) and 90-day (panel B) mortality of the chronic liver failure Consortium (CLIF-C) acute-on-chronic liver failure (ACLF) score compared with Model For End-Stage Liver Disease (MELD), Model For End-Stage Liver Disease sodium score (MELD-Na) and Child-Pugh-Turcotte scores (CPs). Adapted with permission from Jalan et al. ${ }^{10}$

\section{A Prediction of 28-day mortality}

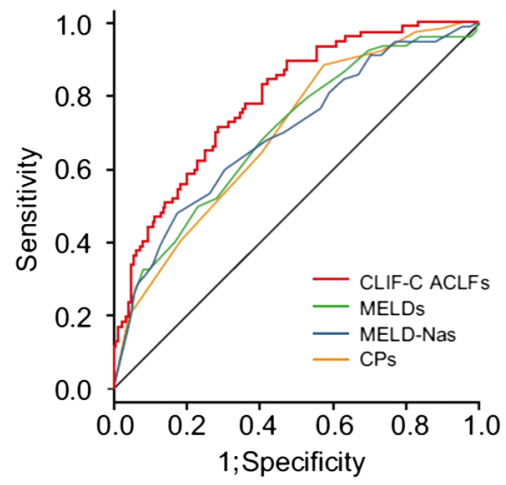

\begin{tabular}{llll}
\hline & & $\begin{array}{l}\text { AUROC } \\
(95 \% \mathrm{Cl})\end{array}$ & $\begin{array}{l}p \text { value; } \\
\text { vs; CLIF-C ACLF }\end{array}$ \\
\hline- & CLIF-C ACLFs & $0.79(0.73-0.85)$ & \\
- & MELDs & $0.70(0.62-0.77)$ & 0.0089 \\
- & MELD-Nas & $0.70(0.62-0.77)$ & 0.0097 \\
$-\quad$ CPs & $0.70(0.63-0.77)$ & 0.0075 \\
\hline
\end{tabular}

\section{B Prediction of 90-day mortality}

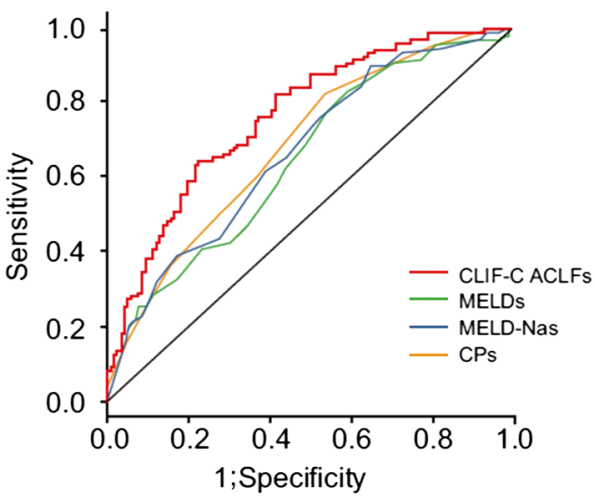

\begin{tabular}{llll}
\hline & & $\begin{array}{l}\text { AUROC } \\
(95 \% \mathrm{Cl})\end{array}$ & $\begin{array}{l}p \text { value; } \\
\text { vs; CLIF-C ACLF }\end{array}$ \\
\hline- & CLIF-C ACLFs & $0.76(0.70-0.83)$ & \\
- & MELDs & $0.65(0.58-0.72)$ & 0.0014 \\
- & MELD-Nas & $0.67(0.60-0.74)$ & 0.0082 \\
- & CPs & $0.69(0.62-0.75)$ & 0.0301 \\
\hline
\end{tabular}




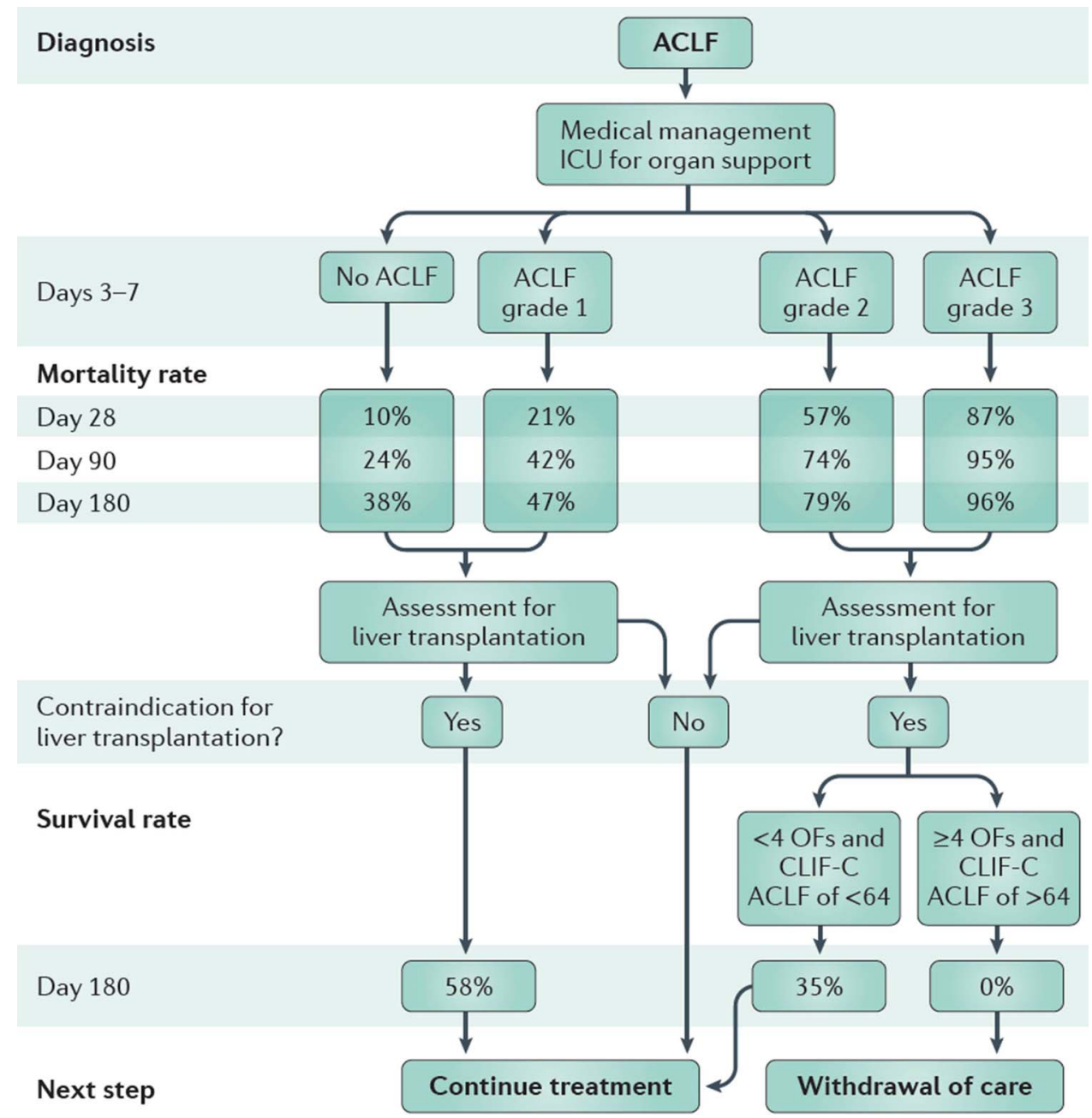

Figure 4 Proposed algorithm for the management of patients with acute-on-chronic liver failure (ACLF) or decompensated cirrhosis. A proposed management strategy for patients with ACLF based on mortality rate data from the CANONIC study. ${ }^{8}$ The first step is the assessment of ACLF grade at days 3-7 after initiation of medical management, including organ support. Liver transplantation should be assessed in all patients with ACLF because of high 90-day mortality rates (>20\%). Liver transplantation should be performed as early as possible in patients with ACLF grade 2 and grade 3 as they are at considerable risk of short-term (28-day) mortality. In the case of contraindication of liver transplantation, the presence of four or more organ failures (OFs) or a Chronic Liver Failure Consortium (CLIF-C) ACLF score of $>64$ at days 3-7 after diagnosis could indicate the futility of care. ICU, intensive care unit. Adapted from Gustot et $a^{51}$ and obtained from Arroyo et $a l^{27}$ with permission.

transplant centre. Organ function should be monitored frequently and early treatment provided according to each specific organ in order to avoid a stage of multiple OF. General management should be based on current guidelines and recent reviews on the management of critically ill patients with cirrhosis. ${ }^{52} 53$ Therefore, this review will focus only on specific therapies for ACLF.

\section{Specific therapies}

Liver transplantation

LT represents the definitive treatment for patients with ACLF. Therefore, if there are no contraindications, all patients admitted with ACLF should be evaluated for LT. Nevertheless, the use of LT in the context of ACLF is hampered by the shortage of donors and also by the high frequency of contraindications that these patients may present ('too sick to transplant'). Due to a high MELD score, these patients can have rapid access to transplant. However, the final indication for LT should be reconsidered according to standard criteria such as presence of active infections, comorbidities or psychological aspects and also according to the progression of ACLF during admission.
As described above, exceedingly high CLIF-C ACLF score during the course of the disease may help establish futility criteria. $^{1051}$

Data on LT and outcome in patients with ACLF are scarce and interpretation may be difficult due to different ACLF definitions and short series of patients. Data from the CANONIC study are limited as only few patients were transplanted, $9 \%$ within 28 days and 15\% within 90 days after admission. In patients with ACLF grade 2 or 3, survival without LT was $<20 \%$, but increased to $80 \%$ in those patients who received LT, results comparable with those patients transplanted without ACLF. In this cohort, the median delay between ACLF diagnosis and LT was 11 (1-28) days. ${ }^{9}$ Another study that included 238 patients used intention-to-treat analysis and showed a 5 -year post-LT survival of $>80 \%$ for patients eligible for LT. ${ }^{54}$ However, it should be noted that LT was feasible in $<25 \%$ of patients' cohort, as many patients could not be transplanted due to age, active alcoholism, active infections or other comorbidities.

The timing of transplantation is crucial particularly in patients with ACLF, as these patients may provide a short window of opportunity due to the risk of development of multiorgan 
failure precluding LT. Considering the good outcomes described so far, it could be suggested to include high-risk patients with ACLF as an indication for high urgency allocation for LT. However, this may be controversial and is still not performed in most countries, but it is an option that could be studied in future studies.

\section{Liver support systems}

Extracorporal liver support systems, particularly albumin dialysis and/or plasma exchange have been proposed as new therapeutic options that could be used as a bridge to LT in patients with ACLF. $^{55-58}$ These systems are aimed at improving clinical, neurological and biological parameters. These improvements could allow waiting for LT in better conditions. Trials performed to evaluate the usefulness of these liver support systems usually include a heterogeneous population of patients with decompensated cirrhosis associated with different degrees of $\mathrm{OF}$. However, to date there are no studies evaluating these devices using the current definition of ACLF.

The most studied liver support devices include molecular adsorbent recirculating system (MARS) and plasma separation and absorption system (Prometheus), which are based on the principles of albumin dialysis. Prospective trials have shown that MARS is able to improve cholestasis, liver and kidney function and haemodynamics in patients with decompensated cirrhosis; however, the effect on survival is not conclusive. ${ }^{56-58} \mathrm{~A}$ muticentre European randomised controlled trial (RCT) of MARS compared with standard medical therapy (SMT) in patients with ACLF was recently reported (RELIEF trial). In this trial, ACLF was defined as bilirubin $>5 \mathrm{mg} / \mathrm{dL}$ associated with at least one of the following: HE grade 3-4, hepatorenal syndrome and bilirubin $>20 \mathrm{mg} / \mathrm{dL}$. The most common precipitating events in this population were alcohol abuse and bacterial infections. In summary, there were no differences in 28-day or 90-day transplant-free survival between MARS and SMT groups. ${ }^{58}$

Another multicentre European RCT evaluated Prometheus in patients with ACLF. This was the Helios trial that defined ACLF as patients with cirrhosis and Child-Pugh score $>10$ and bilirubin $>5 \mathrm{mg} / \mathrm{dL}$. Results showed that the approach was safe and well tolerated but there is no survival benefit at 28 days. ${ }^{55}$

Overall, heterogeneity of patients and definitions and duration of treatment and modalities makes difficult to evaluate the usefulness of these devices particularly in patients with ACLF. Therefore, further RCT with homogenous definition of the syndrome are needed to re-evaluate the effect of liver support systems on survival.

\section{Future perspectives: pathophysiologial-based treatments}

Considering that currently there is no specific treatment for the management of ACLF, research should be based on potential new treatments addressed to pathophysiological mechanisms leading to the development of the syndrome. Large body of evidence from the last decades suggests that bacterial translocation (BT) and an excessive systemic inflammation are the key mechanisms leading to the progression of cirrhosis and the development of ACLF. Therapeutic interventions acting on BT (ie, probiotics, norfloxacin, rifaximin) would probably act in the prevention of the development of ACLF rather than in the management of the syndrome itself once it has developed. In contrast, therapeutic interventions addressed to mitigate the excessive systemic inflammation and to restore the immunological response should be investigated as potential treatment options.
On this background, innovative therapies based on immunomodulatory or liver regenerative effects have been proposed as new therapeutic approaches, including administration of granulocyte-colony stimulating factor (G-CSF) and stem cell transplantation.

G-CSF therapy in ACLF is only based on two randomised clinical trials. Garg et $a l^{11}$ randomised 47 patients to $5 \mu \mathrm{g} / \mathrm{kg}$ G-CSF subcutaneously $(\mathrm{n}=23)$ vs placebo/standard medical care $(\mathrm{n}=24)$ and found that the probability of survival at day 60 was $66 \%$ vs $26 \%$, respectively $(\mathrm{p}=0.001)$. Other parameters such as the Child-Pugh-Turcotte and SOFA scores improved and patients receiving G-CSF were less likely to develop hepatorenal syndrome, HE or sepsis. In another study, Duan et $a l^{59}$ randomised 55 patients with HBV-associated ACLF to G-CSF vs placebo/ standard of care. The probability of survival at 90 days was $48 \%$ in the G-CSF group compared with $21.4 \%$ in the placebo group. Similar to the study by Garg et al, patients on G-CSF achieved reduction in MELD score. Side effects were mild and expected from the use of G-CSF (nausea, vomits, fever, rash). Overall, the use of G-CSF in patients with ACLF is still experimental as it has been used in 102 patients but the results are encouraging.

There is only one stem cells trial in humans. Shi et $a l^{60}$ using an open-label controlled trial enrolled 43 hepatitis B patients with ACLF to receive umbilical cord-derived mesenchymal stem cells (UC-MSC, $\mathrm{n}=24$ ) vs 19 patients with saline as controls. After 90 days, $79.2 \%$ on the UC-MSC survived vs $52.5 \%$ in the control group. MELD scores also decreased over time (in both groups) but more in the UC-MSC (10 vs $15, \mathrm{p}=0.04)$. Self-limited fever from UC-MSC was reported, but no other significant side effects.

Overall, both therapies (G-CSF and stem cells) showed encouraging results, but the optimism is limited by the small number of participants.

\section{Prevention of ACLF: syndrome awareness, identification of predisposing conditions and careful clinical examination}

Nowadays, it is difficult to prevent ACLF unless the clinician is aware of the syndrome and its clinical implications. Initiatives such as this one, cohort studies (CANONIC, NACSELD) and group consensus (APASL, WGO) help in the identification of the syndrome. Borrowing terms from preventive medicine, the current management of ACLF is a tertiary or, at its best, secondary prevention. In other words, once ACLF have occurred, the following days will determine whether the patient will undergo recovery or not with full medical support including evaluation for liver transplant (tertiary prevention). In some occasions, only one organ has failed and the aim is to prevent further OF involvement by providing aggressive medical care (eg, antibiotics to prevent hepatorenal syndrome in the setting of gastrointestinal bleeding (GIB)). Preventing other OFs is an example of secondary prevention (damage is present but aiming to reduce further damage).

It is the grail of ACLF treatment, however, to prevent the onset of syndrome (primary prevention). APASL has noted a 'golden window', a short period of about 1 week before the onset of sepsis and development of extrahepatic OF in a patient with ACLF. $^{5}$ Interventions during this period are likely to prevent OF and perhaps the development of ACLF ('primary prophylaxis'). Currently, other than the thorough identification, history, physical and pertinent laboratory/imaging studies, there are no other means to detect this 'golden window'.

Prevention of ACLF should be based on treatments targeting the key pathophysiological mechanisms leading to disease 
progression and development of ACLF. Evidence from the last decade suggests that these key mechanisms are mainly the impairment of the gut-liver axis leading to BT and systemic inflammation. Therefore, therapeutic interventions targeting BT and those modulating inflammatory response (ie, norfloxacin, rifaximin, albumin, statins) should be investigated as potential first-line treatments.

Acknowledgements The authors would like to thank Nicki van Berckel, for her administrative support in putting together this paper.

Contributors RH, PG, ES and RM wrote and contributed to this paper equally. Final review and approval was given by all authors.

Funding Some of the work mentioned has been supported by grants awarded to PG (PI12/00330), integrated in the Plan Nacional I+D+I and co-funded by ISCIII-Subdirección General de Evaluación and European Regional Development Fund FEDER; Agencia de Gestió d'Ajuts Universitaris I de Recerca (AGAUR) 2014/SGR 708; PG is a recipient of an ICREA Academia Award. Acknowledgement is made to the LiverHope project, part of the EC H2020-SC1-2016-RTD programme, number: 731875.

Competing interests PG declares that he has received research funding from Ferring Pharmaceuticals, Grifols S.A. and Sequana Medical. He has participated on Advisory Boards for Ferring Pharmaceuticals, Promethera and Novartis.

Provenance and peer review Commissioned; externally peer reviewed.

Open Access This is an Open Access article distributed in accordance with the Creative Commons Attribution Non Commercial (CC BY-NC 4.0) license, which permits others to distribute, remix, adapt, build upon this work non-commercially, and license their derivative works on different terms, provided the original work is properly cited and the use is non-commercial. See: http://creativecommons.org/ licenses/by-nc/4.0/

\section{REFERENCES}

1 Schuppan D, Afdhal NH. Liver cirrhosis. Lancet 2008;371:838-51.

2 Ginés $\mathrm{P}$, Quintero E, Arroyo V, et al. Compensated cirrhosis: natural history and prognostic factors. Hepatology 1987;7:122-8.

3 Kjaergard LL, Liu J, Is-Nielsen B, et al. Artificial and bioartificial support systems for acute and acute-on-chronic liver failure: a systematic review. JAMA 2003;289:217-22.

4 Sarin SK, Kumar A, Almeida JA, et al. Acute-on-chronic liver failure: consensus recommendations of the Asian Pacific Association for the study of the liver (APASL). Hepatol Int 2009:3:269-82.

5 Sarin SK, Kedarisetty CK, Abbas Z, et al. Acute-on-chronic liver failure: consensus recommendations of the Asian Pacific Association for the Study of the Liver (APASL) 2014. Hepatol Int 2014;8:453-71.

6 Wlodzimirow KA, Eslami S, Abu-Hanna A, et al. A systematic review on prognostic indicators of acute on chronic liver failure and their predictive value for mortality. Liver Int 2013;33:40-52.

7 Bajaj JS, O'Leary JG, Reddy KR, et al. Survival in infection-related acute-on-chronic liver failure is defined by extrahepatic organ failures. Hepatology 2014:60:250-6.

8 Jalan R, Yurdaydin C, Bajaj JS, et al. Toward an improved definition of acute-on-chronic liver failure. Gastroenterology 2014;147:4-10.

9 Moreau R, Jalan R, Gines P, et al. Acute-on-chronic liver failure is a distinct syndrome that develops in patients with acute decompensation of cirrhosis. Gastroenterology 2013;144:1426-37, 1437.e1-9.

10 Jalan R, Saliba F, Pavesi M, et al. Development and validation of a prognostic score to predict mortality in patients with acute-on-chronic liver failure. $J$ Hepatol 2014;61:1038-47.

11 Garg V, Garg H, Khan A, et al. Granulocyte colony-stimulating factor mobilizes CD34(+) cells and improves survival of patients with acute-on-chronic liver failure. Gastroenterology 2012;142:505-12.

12 Escorsell Mañosa À, Mas Ordeig A. [Acute on chronic liver failure]. Gastroenterol Hepatol 2010;33:126-34.

13 Sargenti K, Prytz H, Nilsson E, et al. Predictors of mortality among patients with compensated and decompensated liver cirrhosis: the role of bacterial infections and infection-related acute-on-chronic liver failure. Scand I Gastroenterol 2015;50:875-83

14 Shi Y, Yang Y, Hu Y, et al. Acute-on-chronic liver failure precipitated by hepatic injury is distinct from that precipitated by extrahepatic insults. Hepatology 2015;62:232-42

15 Li H, Chen LY, Zhang NN, et al. Characteristics, diagnosis and prognosis of acute-on-chronic liver failure in cirrhosis associated to hepatitis B. Sci Rep 2016;6:25487.
16 Abbas Z, Shazi L. Pattern and profile of chronic liver disease in acute on chronic liver failure. Hepatol Int 2015:9:366-72.

17 Wong RJ, Aguilar M, Cheung R, et al. Nonalcoholic steatohepatitis is the second leading etiology of liver disease among adults awaiting liver transplantation in the United States. Gastroenterology 2015;148:547-55.

18 Du WB, Li LJ, Huang JR, et al. Effects of artificial liver support system on patients with acute or chronic liver failure. Transplant Proc 2005;37:4359-64.

19 Xia Q, Dai X, Zhang Y, et al. A modified MELD model for Chinese pre-ACLF and ACLF patients and it reveals poor prognosis in pre-ACLF patients. PLOS ONE 2013:8:e64379.

20 Kedarisetty CK, Sarin SK, Anand L, et al. Liver failure determines the extra-hepatic organ failure and outcome in patients with acute-on-chronic liver failure: analysis of 1363 patients of AARC Data Base. Hepatology 2014;60:556A.

21 Shi Y, Zheng MH, Yang Y, et al. Increased delayed mortality in patients with acute-on-chronic liver failure who have prior decompensation. J Gastroenterol Hepatol 2015;30:712-8.

22 Wehler M, Kokoska J, Reulbach U, et al. Short-term prognosis in critically ill patients with cirrhosis assessed by prognostic scoring systems. Hepatology 2001;34:255-61.

23 Cholongitas E, Senzolo M, Patch D, et al. Risk factors, sequential organ failure assessment and model for end-stage liver disease scores for predicting short term mortality in cirrhotic patients admitted to intensive care unit. Aliment Pharmacol Ther 2006;23:883-93

24 Bernsmeier C, Pop OT, Singanayagam A, et al. Patients with acute-on-chronic liver failure have increased numbers of regulatory immune cells expressing the receptor tyrosine kinase MERTK. Gastroenterology 2015;148: 603-615.e14.

25 Claria J, Stauber R, Coenraad MJ, et al. Systemic Inflammation in decompensated cirrhosis. Characterization and role in acute on chronic liver failure. Hepatology 2016:64:1249-64.

26 Sole C, Sola E, Morales-Ruiz M, et al. Systemic inflammatory response profile in acute-on-chronic liver failure and its relationship with prognosis. Sci Rep 2016:6:32341.

27 Arroyo V, Moreau R, Kamath PS, et al. Acute-on-chronic liver failure in cirrhosis. Nat Rev Dis Primers 2016:2:16041.

28 Medzhitov R. Origin and physiological roles of inflammation. Nature 2008:454:428-35.

29 Moreau R. The pathogenesis of ACLF: the inflammatory response and immune function. Semin Liver Dis 2016:36:133-40.

30 Gustot T, Durand F, Lebrec D, et al. Severe sepsis in cirrhosis. Hepatology 2009:50:2022-33.

31 Takeuchi 0, Akira S. Pattern recognition receptors and inflammation. Cell 2010;140:805-20.

32 Iwasaki A, Medzhitov R. Control of adaptive immunity by the innate immune system. Nat Immunol 2015;16:343-53.

33 Kono H, Rock KL. How dying cells alert the immune system to danger. Nat Rev Immunol 2008:8:279-89.

34 Gabay C, Kushner I. Acute-phase proteins and other systemic responses to inflammation. N Eng/ J Med 1999;340:448-54.

35 Medzhitov R. Inflammation 2010: new adventures of an old flame. Cell 2010;140:771-6.

36 Rickard JA, O'Donnell JA, Evans JM, et al. RIPK1 regulates RIPK3-MLKL-driven systemic inflammation and emergency hematopoiesis. Cell 2014;157: $1175-88$.

37 Christaki E, Giamarellos-Bourboulis EJ. The beginning of personalized medicine in sepsis: small steps to a bright future. Clin Genet 2014;86:56-61.

38 Cohen J, Vincent JL, Adhikari NK, et al. Sepsis: a roadmap for future research. Lancet Infect Dis 2015;15:581-614.

39 Byl B, Roucloux I, Crusiaux A, et al. Tumor necrosis factor alpha and interleukin 6 plasma levels in infected cirrhotic patients. Gastroenterology 1993;104: 1492-7.

40 Navasa M, Follo A, Filella X, et al. Tumor necrosis factor and interleukin-6 in spontaneous bacterial peritonitis in cirrhosis: relationship with the development of renal impairment and mortality. Hepatology 1998;27:1227-32.

41 Michelena J, Altamirano J, Abraldes JG, et al. Systemic inflammatory response and serum lipopolysaccharide levels predict multiple organ failure and death in alcoholic hepatitis. Hepatology 2015;62:762-72.

42 Louvet A, Wartel F, Castel H, et al. Infection in patients with severe alcoholic hepatitis treated with steroids: early response to therapy is the key factor. Gastroenterology 2009:137:541-8.

43 Dominguez M, Miquel R, Colmenero J, et al. Hepatic expression of CXC chemokines predicts portal hypertension and survival in patients with alcoholic hepatitis. Gastroenterology 2009;136:1639-50.

44 Medzhitov R, Schneider DS, Soares MP. Disease tolerance as a defense strategy. Science 2012:335:936-41.

45 Jamieson AM, Pasman L, Yu S, et al. Role of tissue protection in lethal respiratory viral-bacterial coinfection. Science 2013:340:1230-4. 


\section{EDITOR'S QUIZ: GI SNAPSHOT \\ Don't mistake it as a polyp!}

\section{ANSWER}

Inverted appendix.

See page 540 for question

Histology of the specimen confirmed the presence of a polypoid mass with a small lumen lined by colonic type epithelium, surrounded by a thick muscularis wall, compatible with an inverted appendix. Scattered endometrial type glands with stroma were also found extending from the mucosa to the serosa, compatible with endometriosis.

Inverted appendix is an uncommon endoscopic finding but an important consideration when faced with a polypoid lesion in the caecal pole. ${ }^{1}$ There are only case reports of this condition, which is more common in adult females in their fourth decade of life. ${ }^{1}$ Endometriosis is a recognised cause of inverted appendix. ${ }^{2}$

The work-up for such lesions should include CT imaging of the abdomen, endoscopic evaluation and histological sampling. Management of an inverted appendix include surgical resection with a limited caecectomy ${ }^{2}$ or endoscopic removal with devices such as endoloops. ${ }^{2}$ Endoscopic removal using diathermy loop should not be attempted due to the potential for perforation. ${ }^{3}$ Endometriosis of the appendix can also present with symptoms of intestinal obstruction from intussusception, symptoms mimicking acute appendicitis or lower GI bleeding. ${ }^{3}$

In addition, the worry of an underlying mucocele of the appendix needs to be considered given its endoscopic findings.

\section{Lim Tian-Zhi, ${ }^{1}$ Faith Leong Qi Hui, ${ }^{1}$ Ker-Kan Tan ${ }^{1,2}$ \\ ${ }^{1}$ Division of Colorectal Surgery, University Surgical Cluster, National University Health System, Singapore, Singapore \\ 2Department of Surgery, Yong Loo Lin School of Medicine, National University of Singapore, Singapore, Singapore}

Correspondence to Dr Lim Tian Zhi, University Surgical Cluster, 1E Kent Ridge Road, National University Health System, Singapore 119228, Singapore; tian_zhi_lim@nuhs.edu.sg

Contributors All three authors are responsible for the collection of clinical information and photos, and are involved in the preparation and drafting of this manuscript.

Competing interests None declared.

Provenance and peer review Not commissioned; externally peer reviewed.

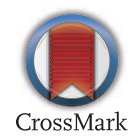

To cite Tian-Zhi L, Leong Qi Hui F, Tan K-K. Gut 2017;66:553.

Received 1 August 2016

Accepted 9 August 2016

Published Online First 8 September 2016

Gut 2017;66:553. doi:10.1136/gutjnl-2016-312704

\section{REFERENCES}

1 Yan $\mathrm{S}$, Yeh $\mathrm{Y}$, Lai $\mathrm{M}$, et al. Inverted appendix in an asymptomatic patient without intussusception or previous appendectomy. Colorectal Dis 2010;12:339-40.

2 Moradi P, Barakate M, Gill A, et al. Intussuception of the vermiform appendix due to endometriosis presenting as acute appendicitis. ANZ I Surg 2007;77:758-60.

3 Hillman L. Gastrointestinal: Colonoscopic removal of an inverted appendix. J Gastroenterol Hepatol 2008;23:1771-1771. 